\title{
Predictive Value of Nutritional Risk Index in Prevalence of Coronary Artery Disease in Chinese Middle-Aged and Older Male Patients
}

\author{
Shijun Li*, Na Li, Xia Huo, Li Zhang and Xiaoying Li
}

Division of Geriatric Cardiology, Chinese PLA General Hospital at No. 28, Fuxing Road, Beijing 100853, PR China.

\begin{abstract}
Objective: Cardiovascular disease and malnutrition may be interrelated, and malnutrition may directly contribute to a fatal outcome. We aimed to evaluate the predictive role of Nutritional Risk Index (NRI) in prevalence of Coronary Artery Disease (CAD) in Chinese middle-aged and elderly male patients.

Methods: Levels of serum albumin, prealbumin and hemoglobin were determined at hospital admission in 197 enrolled patients. The body mass index (BMI) was calculated as weight in kilograms divided by height (meters $\left.{ }^{2}\right)$. The NRI formula as follows: $\mathrm{NRI}=(1.519 \times$ serum albumin, $\mathrm{g} / \mathrm{dL})+(41.7 \times$ present weight $(\mathrm{kg}) /$ ideal body weight $(\mathrm{kg}))$.

Results: There were high levels of albumin and NRI in CAD cases as compared to controls. The percentages of malnutrition in all patients, CAD patients and control cases were $37.56 \%, 33.96 \%$ and $52.63 \%$, respectively. The patients with malnutrition had lower prevalence of coronary artery disease as compared to the patients with better nutrition (69.64\% vs. $86.14 \%)$. NRI value was closely related to prevalence of CAD, and was an independent risk factor for CAD. The area under the curve of NRI was 0.65 , and the Youden index of NRI was 0.33 . The sensitivity and specificity of NRI for predicting prevalence of CAD were $89.18 \%$ and $43.56 \%$, respectively. The optimal diagnosis criterion of NRI for CAD was higher than 45.29.
\end{abstract}

Conclusion: Malnutrition as assessed by NRI is associated with prevalence of CAD, and is a more reliable and independent indicator of prevalence of CAD in Chinese middle-aged and elderly male patients.

Keywords: Malnutrition; Nutritional risk index; Coronary artery disease; Middle-aged; Older male

\section{Introduction}

It is reported that malnutrition is the leading cause of disease burden in developing countries with high morbidity and mortality rates. The prevalence of protein-energy malnutrition increases with age. Some studies showed that $30 \%$ to $50 \%$ of hospitalized patients are described as malnourished or at a risk of malnutrition, with higher rates of malnutrition reported specifically in elderly subjects [1]. Multiple studies have been carried out to explore the association between malnutrition and various chronic diseases such as cancer [2] infections [3] and chronic kidney diseases [4]. Associations have been reported between poor nutritional status and impaired wound healing, increased post-operative complications and mortality [5-7]. Some studies showed that cardiovascular disease and protein energy malnutrition may be interrelated and protein energy malnutrition may directly contribute to a fatal outcome $[8,9]$. A previous study showed that protein energy malnutrition and atherosclerosis are interrelated [10]. Therefore, there is a rationale to routinely screen patients for nutritional risk and risk for complications at hospital admission [11].

The nutritional makers such as BMI, hemoglobin, albumin and prealbumin are often used to evaluate nutrition status in clinical practice previously. Nowadays, numerous researchers have sought a reliable, valid scoring system that can identify patients with poor nutritional status [12]. Many nutrition risk scores to predict nutritionrelated complications in gastrointestinal surgery are available, including the nutrition risk index (NRI), the nutrition risk score, and the bioelectrical impedance analysis [13]. Among them, the NRI, which is based on the serum albumin concentration and weight loss, has been shown to identify patients at risk for postoperative complications [13]. NRI is based on a mathematical equation, can easily be scored after one laboratory test, does not require subjective judgement, and can be safely applied in the clinical setting, with no significant effect on the predictive value [12]. It is well known that diet and lifestyle are closely associated with the development and treatment of coronary heart disease. However, the relationship between protein energy malnutrition and prevalence of coronary artery disease is unclear. Our study aimed to evaluate the predictive value of nutritional risk index in prevalence of coronary artery disease in Chinese middle-aged and elderly male patients.

\section{Methods}

\section{Study population}

The present study was retrospective in design. A total of 300 elderly male patients aged 53 and older were recruited from PLA general hospital during the period of January 2008 to December 2010. The patients who had been lying in bed long-term were excluded due to not measuring height under standing position, and of these 300 patients, 197 were enrolled in the study. All selected patients could take relative drugs according to their condition. Levels of serum albumin, serum prealbumin, serum total protein, serum hemoglobin, and serum lipids were determined at hospital admission. Malnutrition was defined as serum prealbumin level of less than $150 \mathrm{mg} / \mathrm{L}$ and/or serum albumin level of less than $35 \mathrm{~g} / \mathrm{L}$ in our study [14,15]. An informed consent was obtained from all 197 patients prior to enrollment in the study. The Committee on Clinical Research of Chinese PLA General Hospital approved the study protocol.

*Corresponding author: Shijun $\mathrm{Li}$, Division of Geriatric Cardiology, Chinese PLA General Hospital at No. 28, Fuxing Road, Beijing 100853, PR China, Tel: 861066876924; Email: lishijun817@126.com

Received May 30, 2017; Accepted July 14, 2017; Published July 21, 2017

Citation: Li S, Li N, Huo X, Zhang L, Li X (2017) Predictive Value of Nutritional Risk Index in Prevalence of Coronary Artery Disease in Chinese Middle-Aged and Older Male Patients. J Gerontol Geriatr Res 6: 439. doi:10.4172/2167-7182.1000439

Copyright: $\odot 2017 \mathrm{Li} \mathrm{S}$, et al. This is an open-access article distributed under the terms of the Creative Commons Attribution License, which permits unrestricted use, distribution, and reproduction in any medium, provided the original author and source are credited. 


\begin{tabular}{|c|c|c|c|c|}
\hline \multirow{2}{*}{ Variable } & \multirow{2}{*}{ All } & \multicolumn{3}{|c|}{ Groups } \\
\hline & & CAD cases & Controls & $P$ value \\
\hline $\mathrm{N}$ & 197 & 159 & 38 & -- \\
\hline Age (yrs) & $84.6954 \pm 9.70$ & $84.73 \pm 0.75$ & $84.55 \pm 1.75$ & 0.920 \\
\hline Height (m) & $169.548 \pm 5.68$ & $169.57 \pm 0.46$ & $169.46 \pm 1.02$ & 0.916 \\
\hline Weight (kg) & $\begin{array}{c}69.8413 \pm \\
9.69087\end{array}$ & $70.77 \pm 0.80$ & $64.98 \pm 2.44^{* *}$ & 0.007 \\
\hline BMI $\left(\mathrm{kg} / \mathrm{m}^{2}\right)$ & $\begin{array}{l}24.026 \pm \\
4.74517\end{array}$ & $24.38 \pm 0.84$ & $22.23 \pm 1.98^{\star}$ & 0.042 \\
\hline IBM (kg) & $63.46 \pm 11.251$ & $63.47 \pm 1.10$ & $63.44 \pm 0.84$ & 0.990 \\
\hline $\begin{array}{l}\text { Hemoglobin } \\
(\mathrm{g} / \mathrm{L})\end{array}$ & $\begin{array}{c}124.984 \pm \\
19.45\end{array}$ & $125.70 \pm 1.55$ & $122.00 \pm 3.16$ & 0.293 \\
\hline $\begin{array}{l}\text { Total protein } \\
(\mathrm{g} / \mathrm{L})\end{array}$ & $67.03 \pm 6.31$ & $67.27 \pm 0.51$ & $66.04 \pm 0.95$ & 0.281 \\
\hline Albumin $(\mathrm{g} / \mathrm{L})$ & $38.027 \pm 4.776$ & $38.36 \pm 0.38$ & $36.63 \pm 0.69^{*}$ & 0.044 \\
\hline $\begin{array}{l}\text { Prealbumin } \\
\text { (mg/L) }\end{array}$ & $230.919 \pm 8.55$ & $240.48 \pm 0.76$ & $210.62 \pm 1.54$ & 0.095 \\
\hline NRI & $51.46 \pm 6.168$ & $51.98 \pm 0.51$ & $48.77 \pm 1.72^{\star}$ & 0.022 \\
\hline $\begin{array}{l}\text { Hypertension } \\
(\%)\end{array}$ & 83.76 & 84.91 & 78.95 & 0.374 \\
\hline Diabetes $(\%)$ & 43.65 & 44.65 & 39.47 & 0.565 \\
\hline $\mathrm{TC}(\mathrm{mmol} / \mathrm{L})$ & $3.964 \pm 0.854$ & $3.91 \pm 0.07$ & $4.19 \pm 0.15$ & 0.075 \\
\hline $\mathrm{TG}(\mathrm{mmol} / \mathrm{L})$ & $1.435 \pm 0.81$ & $1.42 \pm 0.066$ & $1.487 \pm 0.14$ & 0.672 \\
\hline $\begin{array}{c}\text { LDL-C } \\
(\mathrm{mmol} / \mathrm{L})\end{array}$ & $2.26 \pm 0.73$ & $2.22 \pm 0.06$ & $2.453 \pm 0.12$ & 0.081 \\
\hline $\begin{array}{l}\mathrm{HDL}-\mathrm{C} \\
(\mathrm{mmol} / \mathrm{L})\end{array}$ & $1.09 \pm 0.337$ & $1.09 \pm 0.03$ & $1.10 \pm 0.058$ & 0.830 \\
\hline $\begin{array}{l}\text { Notes: CAD: cc } \\
\text { mass; NRI: nut } \\
\text { low density lipo } \\
\text { lipoprotein-chol }\end{array}$ & $\begin{array}{l}\text { tein (LDL)-chol } \\
\text { terol. *P<0.05; * }\end{array}$ & $\begin{array}{l}\text { lesterol concent } \\
{ }^{*} \mathrm{P}<0.01\end{array}$ & rations; HDL-C: & $\begin{array}{l}\text { ea body } \\
\text { LDL-C: } \\
\text { density }\end{array}$ \\
\hline
\end{tabular}

Table 1: Clinic characteristics of the patients.

\begin{tabular}{|c|c|c|c|}
\hline & Controls $(\mathbf{n}=123)$ & Cases with malnutrition $(\mathbf{n}=\mathbf{7 4})$ & P value \\
\hline BMI $\left(\mathrm{kg} / \mathrm{m}^{2}\right)$ & $24.58 \pm 0.44$ & $22.46 \pm 0.81^{*}$ & 0.017 \\
\hline Hemoglobin $(\mathrm{g} / \mathrm{L})$ & $130.03 \pm 1.77$ & $116.66 \pm 1.90^{* *}$ & 0.000 \\
\hline Albumin $(\mathrm{g} / \mathrm{L})$ & $40.35 \pm 0.30$ & $34.17 \pm 0.50^{* *}$ & 0.000 \\
\hline $\begin{array}{c}\text { Prealbumin } \\
(\mathrm{mg} / \mathrm{L})\end{array}$ & $28.25 \pm 0.93$ & $19.06 \pm 0.64^{* *}$ & 0.000 \\
\hline NRI & $52.63 \pm 0.55$ & $48.13 \pm 1.06^{* *}$ & 0.000 \\
\hline
\end{tabular}

Notes: BMI: body mass index; NRI: nutrition risk index. ${ }^{*} \mathrm{P}<0.05 ;{ }^{* *} \mathrm{P}<0.01$

Table 2: Comparison of nutritional markers between controls and cases with malnutrition.

\section{Measurements}

Anthropometric measures: All measurements were taken at the hospital admission. Body weight (BW) was measured to the nearest 0.1 $\mathrm{kg}$ (Weight Tronix, New York, NY, USA) and height to the nearest 0.5 $\mathrm{cm}$ using a stadiometer (Holtain; Crosswell, Wales). Ideal BW (IBW) was calculated according to the Lorentz formula that takes into account patient's height and sex as follows: IBW $(\mathrm{kg})=$ height $(\mathrm{cm})-100-\{$ [height (cm)-150]/4\}. The Body Mass Index (BMI: kilograms/meters ${ }^{2}$ ) was calculated as weight in kilograms divided by height (meters $\left.{ }^{2}\right)$.

Laboratory measures: Blood samples for serum total protein, serum albumin, serum prealbumin, serum hemoglobin and serum lipids levels were drawn on admission. Serum hemoglobin was routinely measured as part of a routine blood test termed complete blood count using fully automated blood-cell analyzers (Lonsino Medical Products Co., Ltd., Jiangsu, China). Serum total protein, serum albumin, serum prealbumin were measured by a commercial kit (Abbott, IL, USA) using an automatic analyser (Aoreset, Abbott, IL, USA). Serum total cholesterol (TC), triglyceride (TG), low density lipoprotein (LDL)cholesterol concentrations, and high-density lipoprotein (HDL)- cholesterol concentrations were measured by automated chemistry analyzer (Aeroset, Abbott, ILL, USA) by using commercial kits (Abbott, ILL, USA).

Nutritional risk index: The NRI was originally derived from the serum albumin concentration and the ratio of present to usual $[16,17]$. Faced with the difficulty in identifying the usual body weight of heart failure patients, we alternatively used ideal body weight instead of usual body weight in the NRI formula [18] as follows: NRI $=(1.519 \times$ serum albumin, $\mathrm{g} / \mathrm{dL})+\{41.7 \times$ present weight $(\mathrm{kg}) /$ ideal body weight $(\mathrm{kg})\}$. From these NRI values, we divided all patients into three group: the patients with NRI $<45$; the patients with $45<\mathrm{NRI}$ and $\mathrm{NRI}<50$; the patients with $\mathrm{NRI}<50$.

Statement of ethical approval: The ethical approval of our study was obtained from the ethics committee of the Chinese PLA General Hospital. The reference number is 20130305 . Written informed consent was obtained from all of the subjects included in the study.

\section{Statistical Analysis}

Statistical analysis was performed using a standard statistical software package (SPSS for Windows, version 17; SPSS; Chicago, IL, USA) and Medcalc software package (version 12.3.0.0; Belgium). Continuous variables are expressed as the mean \pm SD. Patient groups were compared using Student's $t$-test (for normally distributed variable) and the $\mathrm{X}^{2}$ test for categorical variables. Multiple logistic regressions were used to determine the association between nutritional risk factors and coronary artery disease. Receiver operating characteristic (ROC) curves and Youden index J were used to obtain the biomarker cutoff points for predicting the prevalence of coronary artery disease. A P-value of less than 0.05 was considered statistically significant.

\section{Results}

\section{Clinic characteristics of the enrolled cases}

The clinic characteristics of our study participants $(n=197)$ were shown in Table 1. The patients were divided into two groups according to whether coronary artery disease or malnutrition was present or not. The mean age of CAD cases was not significantly different as compared with controls. There were high levels of the weight, BMI, albumin, and nutritional risk index in CAD cases as compared to controls. The IBW values, serum hemoglobin, serum total protein, and serum prealbumin were not significantly different as compared with controls. In addition, the histories of hypertension and diabetes weren't significantly different in CAD cases compared with controls. The lipid markers such as TC, TG, LDL-C and HDL-C weren't significantly different in CAD cases compared with controls (Table 1). The percentages of malnutrition in all patients, CAD patients and control cases were $37.56 \%, 33.96 \%$ and $52.63 \%$, respectively. As compared with control cases, the BMI, hemoglobin, albumin, prealbumin and NRI in cases with malnutrition were lower (Table 2).

\section{Effect of malnutrition on prevalence of coronary artery diseases}

All patients were classified as two groups of patients with better nutrition and ones with malnutrition according to whether serum prealbumin level of less than $150 \mathrm{mg} / \mathrm{L}$ and an albumin level of less than $35 \mathrm{~g} / \mathrm{L}$ were or not. We performed the $\mathrm{X}^{2}$ test to understand the role of malnutrition on prevalence of coronary artery diseases. The results showed that the patients with malnutrition had lower prevalence of coronary artery disease as compared to the patients with better nutrition $(69.64 \%$ vs. $86.14 \%)$. Numerous measures had 
been developed to assess the nutritional status of the hospitalized patients. Among them, the NRI was developed by the veterans affairs total parenteral nutrition cooperative study group. Based on the NRI values, we defined all patients as three grades of nutrition-related risk: i) patients with $\mathrm{NRI}<45$; ii) patients with NRI 45-50; iii) patients with NRI $>50$. Our study revealed that the patients with $\mathrm{NRI}<45$ had lower percentage of coronary artery disease as compared to the patients with NRI $45-50$ (58.44\% vs. $84.39 \%)$ or NRI $>50$ ( $58.44 \%$ vs. $83.26 \%)$.

\section{Relationship between nutrition-related markers and coronary artery diseases}

BMI, hemoglobin, albumin, prealbumin and NRI were often used to evaluate nutrition condition in clinical practice. To identify what nutritional-related markers were closely related to coronary artery diseases, we performed binary logistic regression analysis. All patients were divided into two groups according to whether NRI was less than 45 , serum hemoglobin was less than $120 \mathrm{~g} / \mathrm{L}$, serum albumin was less than $35 \mathrm{~g} / \mathrm{L}$ or serum prealbumin was less than $150 \mathrm{mg} / \mathrm{L}$. Our results showed that NRI was closely related to coronary artery diseases, and was an independent risk factor for coronary artery diseases. The variables such as BMI group, hemoglobin group, albumin group and prealbumin group were excluded from the equation. (Table 3 )

\section{Predictive value of nutritional risk index in prevalence of} coronary artery diseases

The respective cut-off points of malnutrition-related markers

\begin{tabular}{|c|c|c|c|c|c|}
\hline & B & S.E. & Wald & P value & Exp (B) \\
\hline Age & -0.004 & 0.020 & 0.048 & 0.827 & 0.996 \\
\hline TC & -0.323 & 0.565 & 0.326 & 0.568 & 0.724 \\
\hline TG & -0.014 & 0.319 & 0.002 & 0.965 & 0.986 \\
\hline LDLC & -0.070 & 0.572 & 0.015 & 0.903 & 0.932 \\
\hline HDLC & 0.216 & 0.802 & 0.072 & 0.788 & 1.241 \\
\hline Hypertension & -0.405 & 0.455 & 0.793 & 0.373 & 0.667 \\
\hline Diabetes & -0.213 & 0.368 & 0.334 & 0.563 & 0.808 \\
\hline NRI group & -1.530 & 0.616 & 6.169 & 0.013 & 0.216 \\
\hline BMl group & 0.353 & 0.640 & 0.305 & 0.581 & 1.424 \\
\hline $\begin{array}{c}\text { Hemoglobin } \\
\text { group }\end{array}$ & -0.378 & 0.702 & 0.289 & 0.591 & 0.685 \\
\hline Albumin group & -0.375 & 0.697 & 0.290 & 0.590 & 0.687 \\
\hline $\begin{array}{c}\text { Prealbumin } \\
\text { group }\end{array}$ & -1.250 & 0.762 & 2.692 & 0.101 & 0.287 \\
\hline Constant & 2.041 & 0.336 & 36.877 & 0.000 & 7.700 \\
\hline Notes: CAD:
\end{tabular}

Notes: CAD: coronary artery disease; BMI: body mass index; NRI: nutritional risk index; TC: total cholesterol; TG: triglyceride; LDL-C: low density lipoprotein (LDL)-cholesterol concentrations; HDL-C: high density lipoprotein-cholesterol. All patients were divided in two groups according to whether NRI was less than 45 , hemoglobin was less than $120 \mathrm{~g} / \mathrm{L}$, albumin was less than $35 \mathrm{~g} / \mathrm{L}$ or prealbumin was less than $150 \mathrm{mg} / \mathrm{L}$. The variable such as NRI group was in the equation and the variables such as BMI group, hemoglobin group, albumin group and prealbumin group were excluded from the equation.

Table 3: Binary logistic regression analysis for independent risk factor for predicting CAD.

\begin{tabular}{|c|c|c|c|c|c|c|}
\hline & Area & $\begin{array}{c}\text { Std. } \\
\text { Error }^{\mathbf{a}}\end{array}$ & $\begin{array}{c}\mathbf{P} \\
\text { value }\end{array}$ & Youden index J & Sensitivity & Specificity \\
\hline NRI & 0.65 & 0.07 & 0.000 & 0.33 & $89.18 \%$ & $43.56 \%$ \\
\hline BMI & 0.65 & 0.07 & 0.028 & 0.34 & $89.16 \%$ & $42.28 \%$ \\
\hline Prealbumin & 0.64 & 0.06 & 0.020 & 0.29 & $86.90 \%$ & $33.98 \%$ \\
\hline Albumin & 0.61 & 0.05 & 0.020 & 0.25 & $87.85 \%$ & $27.77 \%$ \\
\hline Hemoglobin & 0.56 & 0.05 & 0.210 & 0.17 & $86.35 \%$ & $24.07 \%$ \\
\hline Notes: NRI: nutrition risk index; BMI: body mass index \\
\hline
\end{tabular}

Table 4: ROC curve analysis for sensitivity and specificity of nutritional makers for predicting prevalence of coronary artery disease.
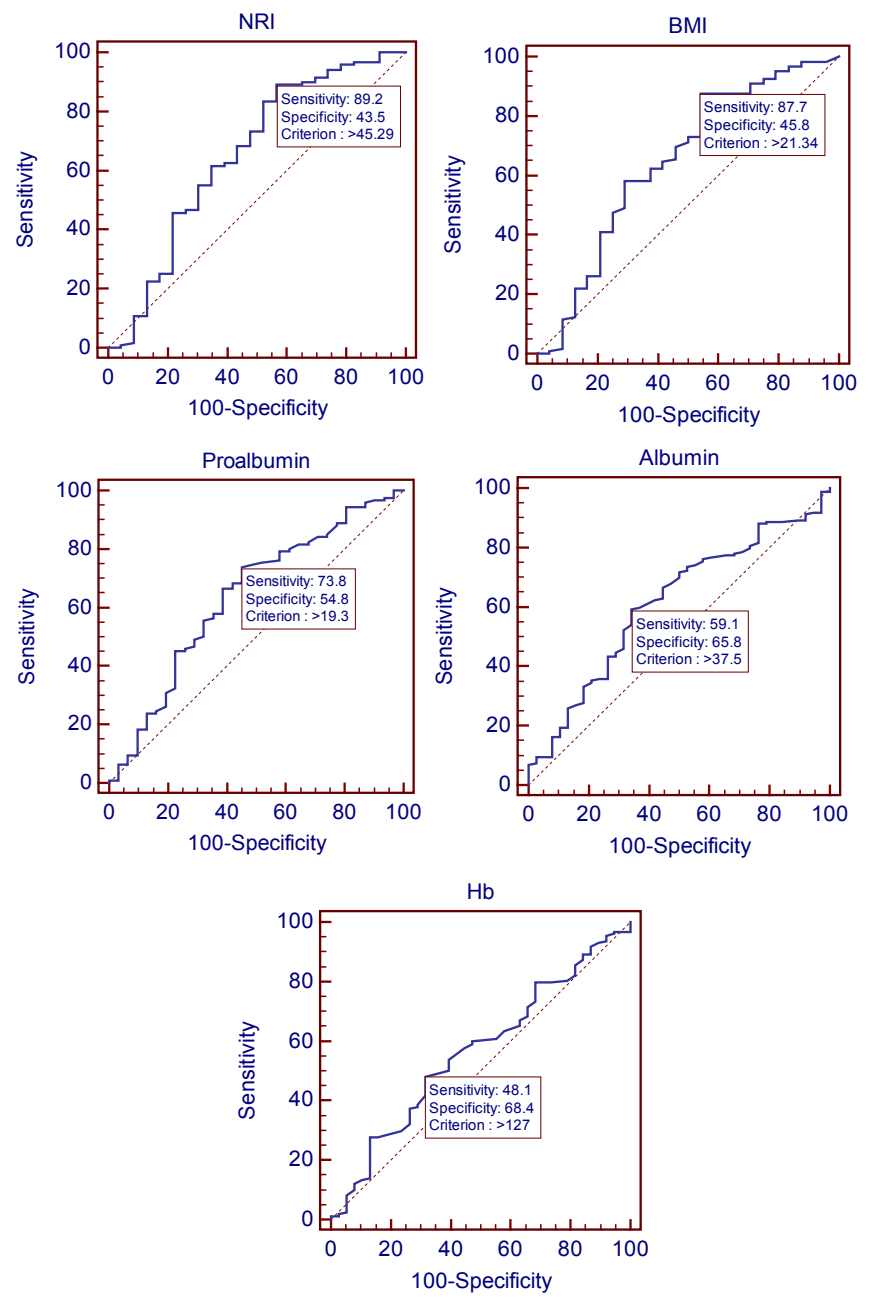

Notes: NRI: nutrition risk index; BMI: body mass index; $\mathrm{Hb}$ : hemoglobin.

Figure 1: ROC curve analysis for sensitivity and specificity of nutritional makers for predicting prevalence of coronary artery disease.

including NRI, BMI, prealbumin, albumin and hemoglobin for predictive value of coronary artery diseases were estimated according to the ROC curves. The current study showed that the areas under the curves of NRI, BMI, prealbumin, albumin and hemoglobin were 0.65 , $0.65,0.64,0.61,0.61$ and 0.56 , respectively. The Youden index values of NRI, BMI, prealbumin, albumin and hemoglobin were $0.33,0.34,0.29$, 0.25 and 0.17 , respectively. The sensitivity and specificity values of NRI, BMI, prealbumin, albumin and hemoglobin were presented in Table 4. NRI and BMI had higher sensitivity and lower specificity for predicting coronary artery disease. (Table 4 and Figure 1)

\section{Discussion}

Malnutrition was reported to be the leading cause of disease burden in developing countries with high morbidity and mortality rates. The prevalence of malnutrition had been estimated to be as high as $50 \%$ among acutely hospitalized adults, depending on the definition employed and the population assessed [19,20]. Malnutrition was consistently associated with adverse clinical outcomes, including increased morbidity, mortality and length of hospital stay, and reduced quality of life $[21,22]$. Malnutrition was a common problem in elderly population at hospital admissions according to different methods used. According to mini nutritional assessment, $69 \%$ of patients had risk 
associated to malnutrition ( $18 \%$ at high risk and $50 \%$ at moderate risk). $46 \%$ and $20 \%$ of patients were classified at moderate malnutrition and severe malnutrition, respectively using the subjective global assessment [23]. Study of Pirlich et al. showed that patients with malignancies, inflammatory bowel disease, chronic heart failure and benign lung diseases need special attention due to the high prevalence of malnutrition. Malnutrition was present in $24.2 \%$ of all patients. High prevalence rates $>30 \%$ were observed in subgroups of patients with inflammatory bowel diseases, chronic heart failure and benign lung diseases [24]. A study from China disclosed that the prevalence of malnutrition in hospitalized surgical patients was high. Malnutrition rate of all patients according to BMI, triceps skinfold (TSF), Mid-arm circumference (MAC), arm muscle circumference (AMC), albumin, prealbumin, and lymphocyte count was $21.3 \%, 50.6 \%, 20.5 \%, 21.2 \%, 24.2 \%, 35.4 \%$ and $55.8 \%$, respectively. The prevalence of malnutrition as defined by subjective global assessment (SGA) and mini nutritional assessment (MNA) were $38.8 \%$ and $20.8 \%$. The older patients ( $>60$ years old) were associated with a higher prevalence of malnutrition (47.6\%) compared with those younger than $60(31.5 \%)$. Malnutrition was associated with increased length of stay, higher operative morbidity and complications [25]. Our study showed that the percentage of malnutrition in all elderly male patients was $37.56 \%$, and the percentages of malnutrition in CAD patients and control cases were $33.96 \%$ and $52.63 \%$, respectively.

Nutritional status was often assessed by body mass index $\left(\mathrm{BMI}<22.0 \mathrm{~kg} / \mathrm{m}^{2}\right.$, undernutrition; $\mathrm{BMI}>27.0 \mathrm{~kg} / \mathrm{m}^{2}$, overnutrition), hemoglobin (hemoglobin $<120 \mathrm{~g} / \mathrm{dl}$, undernutrition; hemoglobin $>120$ $\mathrm{g} / \mathrm{dl}$, undernutrition), albumin, and prealbumin. Amongst patients with suspected CAD referred for coronary computed tomography angiography (CCTA), individuals with increased BMI had greater prevalence, extent, and severity of CAD that was not fully explained by the presence of traditional risk factors. A higher BMI was independently associated with increased risk of intermediate-term risk of myocardial infarction [26]. Our study showed that the BMI in cases with malnutrition was lower than in control cases, and the BMI in CAD cases was higher as compared with control cases. However, BMI wasn't an independent risk factor for coronary artery disease. The association between obesity and CAD may have changed over time, for example due to improved pharmacological treatment of CAD risk factors. A meta-analysis of 31 prospective cohort studies explored the influence of calendar period on CAD risk associated with BMI [27].

In addition, low baseline hemoglobin was associated with more comorbidities and could accurately predict 1-year mortality after an acute coronary syndrome [28]. In patients with NSTEMIs and managed with an invasive strategy, a lower hemoglobin level was associated with more extensive coronary artery disease and increased mortality [29]. Few studies reported that the relationship between serum hemoglobin and coronary artery disease. Our study showed that serum hemoglobin level in cases with malnutrition was lower than in controls, however serum hemoglobin in CAD cases was not different as compared with control cases, and serum hemoglobin level wasn't an independent risk factor for coronary artery disease. Previous study showed that lower levels of serum albumin were associated with increased risk of all-cause and cardiovascular mortality as well as with coronary heart disease and stroke incidence [30].

A study demonstrated that albumin, more than body mass index, was associated with mortality and morbidity in isolated CABG recipients and may be a better indicator for outcomes [31]. Few studies reported the association between serum albumin, prealbumin and coronary artery disease. Our study showed that as compared with control cases, serum albumin in cases with malnutrition were lower than in controls, and there was a high level of serum albumin in CAD cases as compared to controls. However, serum albumin level wasn't related to prevalence of coronary disease, and wasn't an independent risk factor for coronary artery disease. In addition, serum prealbumin level in CAD cases wasn't significantly different as compared with controls, and serum albumin level wasn't related to prevalence of coronary disease, and wasn't an independent risk factor for coronary artery disease.

Numerous researchers had sought a reliable, valid scoring system that could identify patients with poor nutritional status [12]. Many nutrition risk scores to predict nutrition-related complications in gastrointestinal surgery were available, including the nutrition risk index (NRI), the nutrition risk score, and the bioelectrical impedance analysis. Among them, the NRI, which was based on the serum albumin concentration and weight loss, had been shown to identify patients at risk for postoperative complications [13]. From these NRI values, we defined four grades of nutrition-related risk: i) major risk $(\mathrm{NRI}<83.5)$; ii) moderate risk (NRI 83.5-97.5); iii) mild risk (NRI 97.5-100); iv) No risk (NRI $>100$ ). The NRI cut-off values were determined according to weight losses of $5 \%, 10 \%$ or $20 \%$. The weight loss norms of $5 \%$ and $10 \%$ had already been validated by the European Society of Parenteral and Enteral Nutrition (ESPEN) Guidelines for Nutritional Screening [32]. Our study showed that the NRI value in all patients was $51.46 \pm 6.168$, and the NRI values in CAD cases and control cases were $51.98 \pm 0.51$ and $48.77 \pm 1.72$, respectively. From these NRI values, we divided all patients into three groups: the patients with $\mathrm{NRI}<45$; the patients with $45<\mathrm{NRI}$ and $\mathrm{NRI}<50$; the patients with NRI $>50$.

The current study provided evidence that NRI was closely, negatively and independently associated with prevalence of coronary artery disease. The relationship was independent of the other traditional nutritional markers such as BMI, hemoglobin, albumin and prealbumin. Moreover, we sought a cut-off point of NRI that would predict prevalence of coronary artery disease. The NRI value of 45.29 was the best cut-off point for predicting prevalence of coronary artery disease in the current study. The NRI value had a higher sensitivity for predicting coronary artery disease. On the basis of these results, NRI appeared to be a new marker for predicting CAD. Lower prevalence of coronary artery disease might be explained in Chinese elderly male patients with reduced NRI.

\section{Conclusion}

In conclusion, nutritional risk index was associated with prevalence of coronary artery disease, and the NRI was a more reliable and independent indicator of prevalence of coronary artery disease, and the NRI value of 45.29 was the best cut-off point for predicting prevalence of coronary artery disease in Chinese middle-aged and elderly male patients.

\section{Acknowledgements}

The authors gratefully acknowledge the staff of the Geriatric Cardiovascular Division of Chinese PLA General Hospital for their helpful suggestions and for collecting the clinical data. This research did not receive any specific grant from any funding agency in the public, commercial, or not-for-profit sector. Funding statement: This research did not receive any specific grant from any funding agency in the public, commercial, or not-for-profit sector.

\section{References}

1. Edington J, Boorman J, Durrant ER, Perkins A, Giffin CV, et al. (2000) Prevalence of malnutrition on admission to four hospitals in England. The malnutrition prevalence group. Clin Nutr 19: 191-195.

2. Paccagnella A, Morello M, Da Mosto MC, Baruffi C, Marcon ML, et al. (2010) 
Early nutritional intervention improves treatment tolerance and outcomes in head and neck cancer patients undergoing concurrent chemoradiotherapy. Support Care Cancer 18: 837-845.

3. Nassar MF, El-Batrawy SR, Nagy NM (2009) CD95 expression in white blood cells of malnourished infants during hospitalization and catch-up growth. Eas Mediterr Health J 15: 574-583.

4. Bellizzi V, Di lorio BR, Brunori G, De Nicola L, Minutolo R, et al. (2010) Assessment of nutritional practice in Italian chronic kidney disease clinics: A questionnaire-based survey. J Ren Nutr 20: 82-90.

5. Giner M, Laviano A, Meguid MM, Gleason JR (1996) In 1995 a correlation between malnutrition and poor outcome in critically ill patients still exists. Nutrition 12: 23-29.

6. Bidlack WR (1996) Interrelationships of food, nutrition, diet and health: The national association of state Universities and Land Grant Colleges white paper. J Am Coll Nutr 15: 422-433.

7. He J, Gu D, Wu X, Reynolds K, Duan X, et al. (2005) Major causes of death among men and women in China. N Engl J Med 353: 1124-1134.

8. Foley RN, Parfrey PS, Harnett JD, Kent GM, Murray DC, et al. (1996) Hypoalbuminemia, cardiac morbidity, and mortality in end-stage renal disease. J Am Soc Nephro 7: 728-736.

9. Qureshi AR, Alvestrand A, Divino-Filho JC, Gutierrez A, Heimbürger O, et al. (2002) Inflammation, malnutrition, and cardiac disease as predictors of mortality in hemodialysis patients. J Am Soc Nephrol 13 Suppl 1: S28-S36.

10. Yao Q, Lindholm B, Stenvinkel $P$ (2004) Inflammation as a cause of malnutrition, atherosclerotic cardiovascular disease, and poor outcome in hemodialysis patients. Hemodial Int 8: 118-129.

11. Aziz EF, Javed F, Pratap B, Musat D, Nader A, et al. (2011) Malnutrition as assessed by nutritional risk index is associated with worse outcome in patients admitted with acute decompensated heart failure: An ACAP-HF data analysis. Heart Int 6: e2.

12. Kuzu MA, Terzioğlu H, Genç V, Erkek AB, Ozban M, et al. (2006) Preoperative nutritional risk assessment in predicting postoperative outcome in patients undergoing major surgery. World J Surg 30: 378-390.

13. Schiesser M, Kirchhoff P, Müller MK, Schäfer M, Clavien PA (2009) The correlation of nutrition risk index, nutrition risk score, and bioimpedance analysis with postoperative complications in patients undergoing gastrointestinal surgery. Surgery 145: 519-526.

14. Shenkin A (2006) Serum prealbumin: Is it a marker of nutritional status or of risk of malnutrition? Clinical Chemistry 52: 2177-2179.

15. Kuzuya M, Izawa S, Enoki H, Okada K, Iguchi A (2007) Is serum albumin a good marker for malnutrition in the physically impaired elderly? Clin Nutr 26: 84-90.

16. The veterans affairs total parenteral nutrition cooperative study group (1991) Perioperative total parenteral nutrition in surgical patients. N Engl J Med 325: 525-532.

17. Buzby GP, Knox LS, Crosby LO, Eisenberg JM, Haakenson CM, et al. (1988) Study protocol: A randomized clinical trial of total parenteral nutrition in malnourished surgical patients. Am J Clin Nutr 47: 366-381.
18. Bouillanne O, Morineau G, Dupont C, Coulombel I, Vincent JP, et al. (2005) Geriatric Nutritional Risk Index: A new index for evaluating at-risk elderly medical patients. Am J Clin Nutr 82: 777-783.

19. Correia MI, Campos AC (2003) Prevalence of hospital malnutrition in Latin America: The multicenter ELAN study. Nutrition 19: 823-825.

20. Bhghetto MG, Luft VC, Mello ED, Polanczyk CA (2009) Accuracy of nutritiona assessment tools for predicting adverse hospital outcomes. Nutr Hosp 24: 56-62.

21. Goiburu ME, Goiburu MM, Bianco H, Díaz JR, Alderete F, et al. (2006) The impact of malnutrition on morbidity, mortality and length of hospital stay in trauma patients. Nutr Hosp 21: 604-610.

22. Rufenacht $U$, Ruhlin $M$, Wegmann M, Imoberdorf R, Ballmer PE (2010) Nutritional counseling improves quality of life and nutrient intake in hospitalized undernourished patients. Nutrition 26: 53-60.

23. Reyes JG, Zúñiga AS, Cruz MG.(2007) Prevalence of hyponutrition in the elderly at admission to the hospital. Nutr Hosp 22: 702-709.

24. Pirlich M, Schütz T, Kemps M, Luhman N, Burmester GR, et al. (2003) Prevalence of malnutrition in hospitalized medical patients: Impact of underlying disease. Dig Dis 21: 245-251.

25. Wu GH, Liu ZH, Zheng LW, Quan YJ, Wu ZH (2005) Prevalence of malnutrition in general surgical patients: Evaluation of nutritional status and prognosis. Zhonghua Wai Ke Za Zhi 43: 693-696.

26. Labounty TM, Gomez MJ, Achenbach S, Al-Mallah M, Berman DS, et al (2012) Body mass index and the prevalence, severity, and risk of coronary artery disease: An international multicentre study of 13874 patients. Eur Heart $\mathrm{J}$ Cardiovasc Imaging 14: 456-463.

27. De Hollander EL, Bogers RP, Boshuizen HC, Rosengren A, Shipley MJ, et al. (2012) Influence of calendar period on the association between BMI and coronary heart disease: A meta-analysis of 31 cohorts. Obesity (Silver Spring) 21: 865-880.

28. Ferreira M, António N, Gonçalves F, Monteiro P, Gonçalves L, et al. (2012) Hemoglobin: Simply a laboratory value or a powerful predictor of risk in patients with acute coronary syndrome? Rev Port Cardiol 31: 121-131.

29. Hanna EB, Alexander KP, Chen AY, Roe MT, Funk M, Saucedo JF (2013) Characteristics and in-hospital outcomes of patients with non-st-segment elevation myocardial infarction undergoing an invasive strategy according to hemoglobin levels. Am J Cardiol 111: 1099-1103.

30. Shaper AG, Wannamethee SG, Whincup PH (2004) Serum albumin and risk of stroke, coronary heart disease, and mortality: The role of cigarette smoking. J Clin Epidemiol 57: 195-202.

31. Bhamidipati CM, LaPar DJ, Mehta GS, Kern JA, Upchurch GR Jr, et al. (2011) Albumin is a better predictor of outcomes than body mass index following coronary artery bypass grafting. Surgery 150: 626-634.

32. Kondrup J, Allison SP, Elia M, Vellas B, Plauth M (2003) Educational and clinical practice committee, European Society of Parenteral and Entera Nutrition (ESPEN), ESPEN guidelines for nutrition screening 2002. Clin Nutr 22: $415-421$. 